\title{
Numerical Simulation on Residual Stress Field of Flat-Topped Laser Oblique Shocking of Ni-Based Alloy GH4169
}

\author{
Xiangming Qu, Yongkang Zhang $\mathbb{D}$, and Jun Liu \\ School of Electromechanical Engineering, Guangdong University of Technology, Guangzhou 510006, China \\ Correspondence should be addressed to Yongkang Zhang; zykseu@163.com
}

Received 14 September 2020; Revised 15 October 2020; Accepted 30 October 2020; Published 9 December 2020

Academic Editor: José António Fonseca de Oliveira Correia

Copyright ( 92020 Xiangming Qu et al. This is an open access article distributed under the Creative Commons Attribution License, which permits unrestricted use, distribution, and reproduction in any medium, provided the original work is properly cited.

\begin{abstract}
This paper is based on laser shock peening (LSP) system with a flat-topped beam, using robot simulation software to determine the oblique shock angle of different areas of a certain turbine disk mortise. Three-dimensional finite element analysis was used to study residual stress field of Ni-based alloy GH4169 under flat-topped laser oblique shocking. The effects of different laser energy and different shocking number on residual stress field of Ni-based alloy GH4169 of LSP were studied. Three-dimensional finite element analysis used super-Gaussian beam distribution to construct spatial distribution model of shock wave induced by LSP. The simulation results were in good agreement with the experimental results. The research results will provide a theoretical basis for LSP of certain turbine disk mortise.
\end{abstract}

\section{Introduction}

Ni-based alloy GH4169 (equivalent to Inconel 718) has excellent performance in high-temperature environments $[1,2]$ and is often used in the manufacture of aeroengine turbine discs. The turbine discs and the blades of the aeroengine are tightly connected by the tenon and mortise. In the process of aeroengine service, the turbine disc inside the aeroengine drives the blades to rotate at a high speed. During this process, the contact area will generate high-frequency vibration, which can produce a high level of stress concentration. The manufacturing process of the tenon and mortise is easy to form harmful tensile residual stress on surface and inside of material. Stress concentration and tensile residual stress will cause microcracks on surface of the tenon and mortise.

Research showed that $90 \%$ of the failures of in-service metal structures are caused by cracks. Although the formation of initial cracks may not directly lead to destruction of the metal structure, the length of crack affects the retained fatigue life of the metal structure [3]. The residual stress of the material has a significant influence on the crack growth behavior [4]. It is generally believed that the compressive residual stress on the surface can inhibit the initiation and propagation of crack, which is beneficial to prolong the fatigue life $[5,6]$. Compressive residual stress can be obtained by using some surface treatment techniques, such as low plasticity burnishing $[7,8]$, shot peening [9], and LSP $[10,11]$.

There are few researches on LSP in Ni-based alloys. Ren et al. analyzed the thermal relaxation of residual stress in LSP Ni-based alloy GH4169 through finite element analysis [10]. Karthik et al. showed that LSP enhanced corrosion properties in a Ni-based alloy Inconel 600 [12]. Cao et al. studied the high-temperature oxidation resistance of Ni-based alloy GH202 induced by LSP [13]. Kattoura et al. studied the effect of LSP on residual stress, microstructure, and fatigue behavior of ATI 718Plus alloy [14]. Zhou et al. analyzed LSP on Ni-based alloy K417 and its effect on thermal relaxation of residual stress [15]. Xianliang Hu et al. simulated the surface morphology and residual stress field of the Ni-based alloy IN718 by Gaussian mode laser shock [16]. The laser energy distribution in numerical simulation study of LSP mostly adopted the Gaussian beam [15-20]. Due to the characteristics of Gaussian beam, the residual stress field in shock area of material would be unevenly distributed, which would affect the uniformity of shock effect. Converting the Gaussian beam into flat-topped beam with approximately 
uniform energy distribution will improve the uniformity of shock effect.

When LSP is performed on the mortise area of the turbine disk, it is difficult for laser beam to enter perpendicularly due to the narrow space of mortise of turbine disk. The incident angle of laser beam needs to be adjusted to ensure that the laser beam can irradiate the mortise area to be shocked. In this paper, the laser oblique shock angles of different areas of the turbine disk mortise were determined by robot simulation software. The effects of different laser energy and different shocking number on residual stress field of Ni-based alloy GH4169 of LSP were studied through numerical simulation. Finally, the simulation results were compared with the experimental results.

\section{Determine the Angle of Oblique Shock}

Figure 1 is a schematic diagram of the mortise of a certain turbine disk. Due to the narrow structure of the area of the turbine disk mortise, the LSP could only be carried out in oblique incidence. During laser oblique shock, the angle between the beam and the normal of the surface of the area to be shocked was greater than $0^{\circ}$, and the beam spot was elliptical on the surface of the area to be shocked. According to the structural characteristics and strengthening requirements of the turbine disk mortise, the areas that needed laser shock were determined, namely, areas (1), (2), (3), (4), and (5), as shown in Figure 2. In order to adapt to the narrow space of the turbine disc mortise, a small beam spot of $2 \mathrm{~mm}$ was adopted. Using the programming function of the robot simulation software, the range of the oblique shock angle of each area was determined. Table 1 shows the length of the mortise with which the laser beam did not interfere when different angles were used to shock different areas. According to the data in Table 1 , the angle of $60^{\circ}$ was preferentially selected as the oblique shock angle.

\section{Numerical Simulation}

3.1. Material Model. The material model of simulation for LSP is generally defined by the Johnson-Cook (J-C) model $[21,22]$, and the equation is

$$
\sigma=\left(A+B \varepsilon^{n}\right)\left(1+C \ln \varepsilon^{*}\right)\left[1-\left(T^{*}\right)^{m}\right],
$$

where $\sigma$ is the equivalent flow stress; $\mathcal{\varepsilon}$ is the equivalent plastic strain; $\varepsilon^{*}=\left(\varepsilon_{1} / \varepsilon_{0}\right), \varepsilon_{1}$ is plastic strain rate, and $\varepsilon_{0}$ is reference strain rate; $A, B, n, C$, and $m$ are all the material constants; $T^{*}=\left(T-T_{0}\right) /\left(T_{m}-T_{0}\right), T_{0}$ is room temperature, and $T_{\mathrm{m}}$ is the melting point of the material. The parameters of J-C model for Ni-based alloy GH4169 are listed in Table 2 [23].

3.2. Shock Wave Pressure Model of Oblique Shock. In the simulation process, most of the calculation of the pressure model of the laser-induced shock wave adopts Fabbro's model [21-23], and the equation is

$$
P_{0}=0.01 \sqrt{\left(\frac{\alpha}{(2 \alpha+3)}\right)} \sqrt{Z} \sqrt{\left(\frac{E}{(\tau S)}\right)}
$$

where $P_{0}$ is the maximum pressure of shock wave in laser vertical shock; $\alpha$ is the efficiency of the interaction, and the value is $0.25 ; E, \tau$, and $S$ are the laser energy, the spot area, and the pulse width, respectively; $(2 / Z)=\left(1 / Z_{1}\right)+\left(1 / Z_{2}\right)$. $Z_{1}$ is reduced shock impedance of Ni-based alloy GH4169, and the value is $0.32 \times 106 \mathrm{~g} \cdot \mathrm{cm}^{-2} \cdot Z_{2}$ is reduced shock impedance of water confinement layer, and the value is $0.165 \times 106 \mathrm{~g} \cdot \mathrm{cm}^{-2}$.

The spatial distribution of the light intensity of the threedimensional flat-topped beam at $z=0$ is described by superGaussian beam [24], and the expression is

$$
E(x, y, 0)=E_{0} \cdot \exp \left[-2\left(\frac{\sqrt{x^{2}+y^{2}}}{\omega}\right)^{N}\right], \quad N=0,1,2, \ldots,
$$

where $E_{0}$ is the light intensity of the flat-topped beam at the center of the spot; $\omega$ and $N$ are the size and order parameters of the super-Gaussian beam, respectively. When the value of $N$ is 2, the super-Gaussian beam will change to a Gaussian beam, and the value of $N$ was 100 in this paper's simulation calculation of the LSP system in the laboratory. Since the laser energy is proportional to the square of the light intensity, the spatial distribution of the vertical shock wave pressure of the flat-topped beam is expressed as follows:

$$
\begin{gathered}
P=P_{0} \times P(t) \times P(x, y), \\
P(x, y)=\exp \left[-2\left(\frac{\sqrt{\left(x^{2}+y^{2}\right)}}{\omega}\right)^{100}\right],
\end{gathered}
$$

where $P(t)$ is a function of time of shock wave pressure; the time distribution model of shock wave pressure under $20 \mathrm{~ns}$ of pulse width is shown in Figure 3; $P(x, y)$ is the distribution coefficient of super-Gaussian beam; $t$ is the time of shock wave; $(x, y)$ is the coordinate value of the loading point in the numerical model.

When the laser shock is oblique, $P(x, y)$ will be changed with different shock angle [25]. When the shock angle is $60^{\circ}$, the expression of $P(x, y)$ is given as follows:

$$
P_{60}(x, y)=\exp \left[-2\left(\frac{\sqrt{x^{2}+4 \times y^{2}}}{\omega}\right)^{100}\right]
$$

3.3. Finite Element Model. A three-dimensional finite element model was established using ABAQUS software to simulate laser oblique shock processing of $\mathrm{Ni}$-based alloy GH4169. The size of model was $20 \mathrm{~mm} \times 20 \mathrm{~mm} \times 4 \mathrm{~mm}$, as shown in Figure 4 . The model was divided into three areas: shocked region, effected region, and surrounding region. Shocked region was shocked by laser and needed dense mesh to adapt to shock wave; effected region was prone to stress concentration for shock wave, and sufficient mesh density 


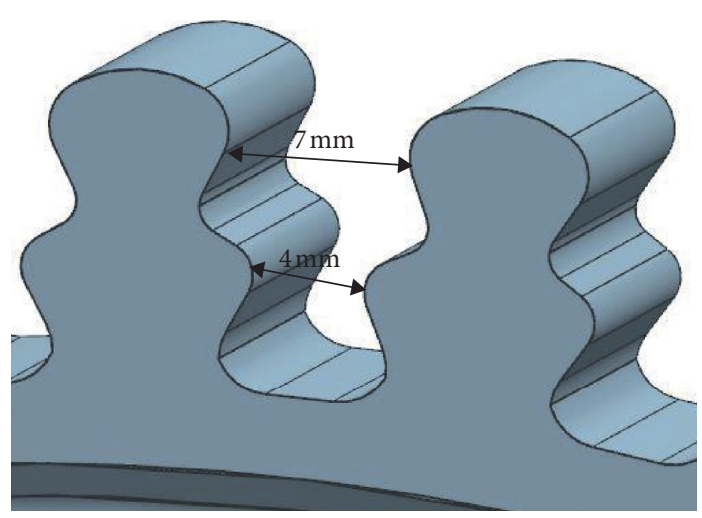

Figure 1: Structural diagram of the mortise of turbine disk.

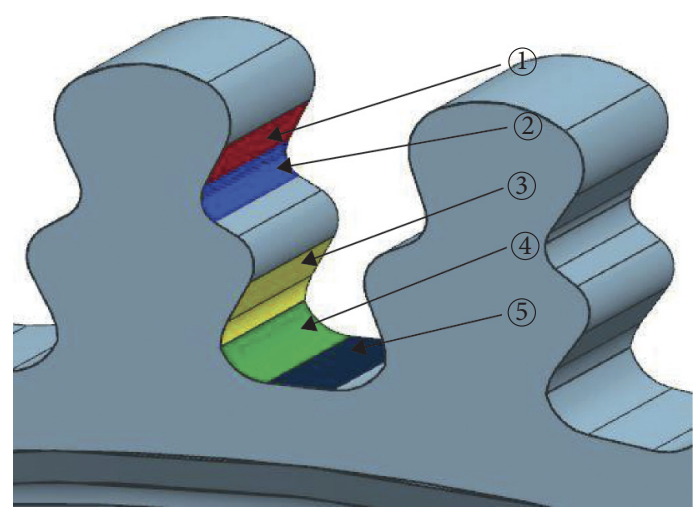

FIGURE 2: LSP area of turbine disk mortise.

TABle 1: Length of the mortise with which laser beam did not interfere $(\mathrm{mm})$.

\begin{tabular}{lccccc}
\hline Shock angle & (1) area & (2) area & (3) area & (4) area & (5) area \\
\hline $0^{\circ}$ & 0 & 13 & 0 & 0 & 13 \\
$10^{\circ}$ & 1 & 13 & 0 & 1 & 13 \\
$20^{\circ}$ & 2 & 13 & 1 & 2 & 13 \\
$30^{\circ}$ & 4 & 13 & 2 & 4 & 13 \\
$40^{\circ}$ & 6 & 13 & 4 & 4 & 13 \\
$50^{\circ}$ & 8 & 13 & 6 & 6 & 13 \\
$60^{\circ}$ & 13 & 13 & 10 & 10 & 13 \\
$70^{\circ}$ & 13 & 13 & 4 & 13 \\
\hline
\end{tabular}

TAble 2: Parameters of J-C model of Ni-based alloy GH4169.

\begin{tabular}{lccccr}
\hline$A(\mathrm{MPa})$ & $B(\mathrm{MPa})$ & $n$ & $C$ & $m$ & $\varepsilon_{0}$ \\
\hline 860 & 1100 & 0.5 & 0.0082 & 1.05 & 1 \\
\hline
\end{tabular}

was required; surrounding region away from the impact of shock wave did not require dense mesh. In order to improve accuracy and efficiency of the calculation results, the mesh size of shocked and effected region was $0.12 \mathrm{~mm} \times 0.12 \mathrm{~mm} \times 0.1 \mathrm{~mm}$, and the mesh size of surrounding region was $0.12 \mathrm{~mm} \times 0.5 \mathrm{~mm} \times 0.1 \mathrm{~mm}$. The whole model was composed of $721320 \mathrm{C} 3 \mathrm{D} 8 \mathrm{R}$ type meshes, as shown in Figure 5. The boundary conditions at the bottom of the model were fully constrained.

\section{Numerical Simulation Results and Discussion}

4.1. Effect of Laser Energy on Residual Stress Field. Three different laser energies were used for comparative analysis, which were $5 \mathrm{~J}, 6 \mathrm{~J}$, and $7 \mathrm{~J}$, and other parameters were kept the same (laser spot diameter of $2 \mathrm{~mm}$, laser pulse width of $20 \mathrm{~ns}$, laser spot overlap rate of $30 \%$, shocking number of 1 , and oblique shock angle of $60^{\circ}$ ). Figure 6 shows contours of residual stress distribution of S11 on surface of a Ni-based 
alloy GH4169 specimen under different laser energy. As laser energy applied to the surface of material increased, the maximum compressive residual stress on the surface of material also increased, respectively: $-296.2 \mathrm{MPa}$, $-373.8 \mathrm{MPa}$, and $-443.5 \mathrm{MPa}$; the maximum compressive residual stress generated by $6 \mathrm{~J}$ increased by $-77.6 \mathrm{MPa}$ compared with $5 \mathrm{~J}, 26.6 \%$ amplitude of increase; the maximum residual compressive stress generated by $7 \mathrm{~J}$ compared with $5 \mathrm{~J}$ increased by $-69.7 \mathrm{MPa}, 18.6 \%$ amplitude of increase. It could be seen that the surface compressive residual stress increased with the increase of laser energy, but the amplitude of increase would slow down. As shown in Figure 6(a), the data of residual stress was extracted at the center line of spot, that is, path $X$, and the residual stress distribution curves are shown in Figure 7. In the process of increasing the laser energy from $5 \mathrm{~J}$ to $7 \mathrm{~J}$, the residual stress field on surface of the material shock region always had some approximately uniformly distributed area, and the uniformity continued to decrease. This was mainly due to the fact that the spatial intensity of flat-topped laser beam is approximately uniform, with uneven distribution, and the unevenness at edge part of the spot is larger than that in the middle part of the spot. With the increase of laser energy, the unevenness of the light intensity will be more obvious [26]. The compressive residual stress on overlapping part of spot was obviously smaller than that on central part of spot, which was mainly caused by the increase of the beam radiation area, the reduction of width of flat-top of beam, and the increase of edge of spot due to oblique incidence of the laser.

Figure 8 shows contours of residual stress distribution of S11 in-depth direction of Ni-based alloy GH4169 specimen under different laser energy. It could be seen from Figure 8 that, after LSP, the Ni-based alloy GH4169 sample would form a certain range of compressive residual stress in-depth direction, and then, through the compressive residual stress, other areas down the range were tensile residual stress. The material formed a range of compressive residual stress in-depth direction of overlapping part of spot that was larger than that of other parts. But, at the same depth, the value of compressive residual stress of material in overlapping part of spot was less than that of center flat-top area of laser. Figure 9 shows the relationship between residual stress field of Ni-based alloy GH4169 specimen and the depth under different laser energy. When the laser energy was $5 \mathrm{~J}$, the value of range of depth of compressive residual stress was about $0.458 \mathrm{~mm}$; when the laser energy was $6 \mathrm{~J}$, the value of range of depth of compressive residual stress was about $0.522 \mathrm{~mm}$; when the laser energy was $7 \mathrm{~J}$, the value of range of depth of compressive residual stress was about $0.561 \mathrm{~mm}$. It could be seen from the above results that as the laser energy increases, the value of range of depth of compressive residual stress affected by laser of material would increase. Therefore, a relatively deep compressive residual stress can be formed inside the material with an appropriate amount of laser energy.

4.2. Effect of the Number of Shocks on Residual Stress. In the application process of LSP, it is difficult to meet the performance requirements of material with only one shock. Taking multiple shocks can improve shortcomings caused by one shock. Three different numbers of shock were used for comparative analysis, namely, 1, 2, and 3, and other parameters were kept the same (laser energy of $5 \mathrm{~J}$, laser spot diameter of $2 \mathrm{~mm}$, laser pulse width of $20 \mathrm{~ns}$, laser spot overlap rate of $30 \%$, and oblique shock angle of $60^{\circ}$ ). Figure 10 shows contours of residual stress distribution of S11 on surface of Ni-based alloy GH4169 specimen under different shocking number. When 1 shock was adopted, the maximum value of compressive residual stress on the material surface was $-296.2 \mathrm{MPa}$; when 2 shocks were adopted, the maximum value of compressive residual stress on the material surface was $-424.0 \mathrm{MPa}$; when 3 shocks were adopted, the maximum value of compressive residual stress on the material surface was $-497.0 \mathrm{MPa}$. The maximum compressive residual stress after 2 shocks increased by $-127.8 \mathrm{MPa}$ compared with 1 shock, $43.1 \%$ amplitude of increase; the maximum residual compressive stress after 3 shocks compared with 2 shocks increased by $-68.4 \mathrm{MPa}$, $17.2 \%$ amplitude of increase. By comparison, it could be seen that as the number of shocks increased, the increase in compressive residual stress on the surface of the material decreased. This is mainly because the increase in number of shock waves on the surface of the material will increase the rigidity and dynamic yield strength of material. It is more difficult for materials to undergo plastic deformation, and more energy is required to cause plastic deformation of materials. The same method of selecting path $X$ as shown in Figure 6(a) was adopted to obtain residual stress distribution curve of material surface with different number of shocks as shown in Figure 11. When the number of shocks increased from 1 to 3, the residual stress field on the surface of material shock area also always had some approximately uniformly distributed areas, and the uniformity continued to decrease. With increase of the number of shocks, the unevenness of light intensity would be more obvious. The compressive residual stress on the overlapping part of the spot was significantly smaller than that on the central part of the spot.

Figure 12 shows contours of S11 residual stress distribution in-depth direction of the Ni-based alloy GH4169 specimen under different number of laser shocks. It could be seen from Figure 12 that, after LSP, the Ni-based alloy GH4169 sample would form a certain range of compressive residual stress in-depth direction, and the range became larger as the number of shocks increased. The distribution curves of residual stress in-depth direction of the material under 1 to 3 shocks are demonstrated in Figure 13. It could be seen from the figure that the value of range of depth of compressive residual stress was about $0.458 \mathrm{~mm}$ when LSP was performed once; the value of range of depth of compressive residual stress was about $0.497 \mathrm{~mm}$ when LSP was performed twice, $8.5 \%$ amplitude of increase compared with 1 shock; the value of range of depth of compressive residual stress is about $0.537 \mathrm{~mm}$ when LSP was performed thrice, $8 \%$ amplitude of increase compared with 2 shocks. From the data above, it could be seen that as number of shocks increased, the amplitude of increase in compressive residual stress on the surface of the material decreased significantly, 


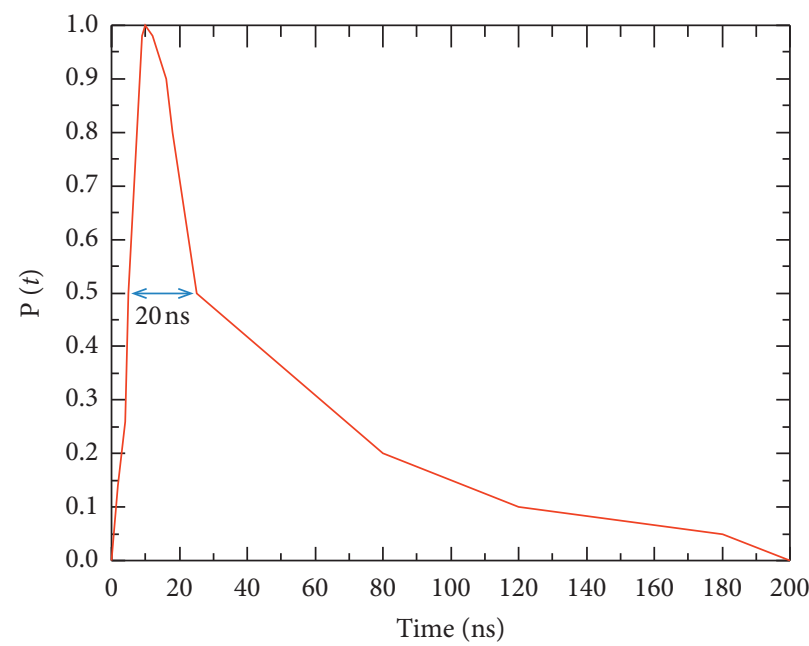

Figure 3: Time distribution model of shock wave pressure.

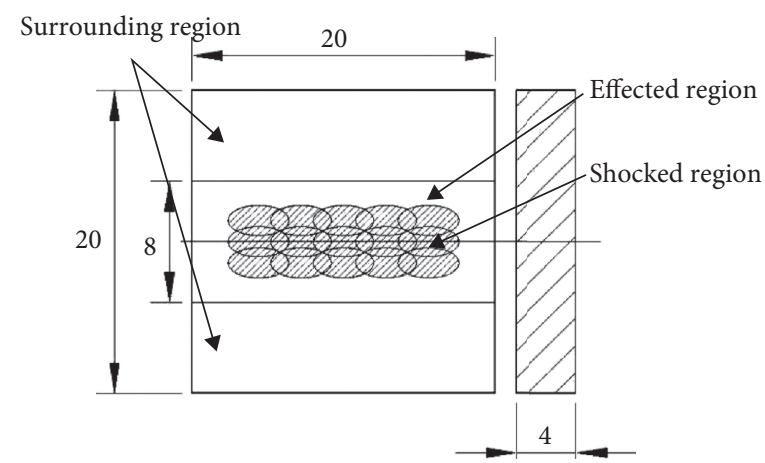

FIGURE 4: Schematic diagram of model size in FEM.

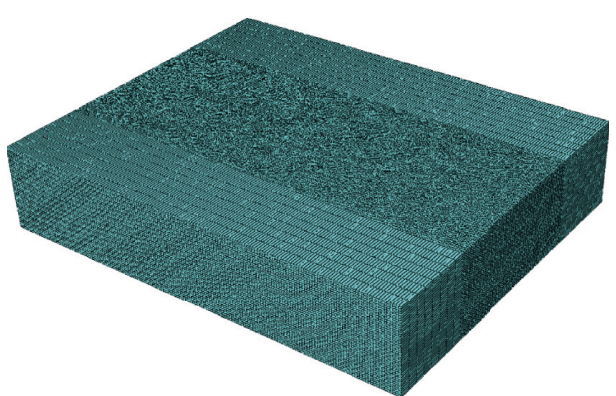

FIGURE 5: Schematic diagram mesh of model.

but the amplitude of increase about the value of range of depth of compressive residual stress did not change significantly.

4.3. Effect of Three Different Laser Energies on Residual Stress Field. In order to study the residual stress distribution of the method of increasing energy after two shocks and the method of gradient energy, combinations of three different energies of LSP were selected. Energy combination I was $5 \mathrm{~J}$, $5 \mathrm{~J}, 5 \mathrm{~J}$; energy combination II was $5 \mathrm{~J}, 5 \mathrm{~J}, 6 \mathrm{~J}$; energy combination III was $5 \mathrm{~J}, 6 \mathrm{~J}, 7 \mathrm{~J}$; energy combination IV was
$7 \mathrm{~J}, 7 \mathrm{~J}, 7 \mathrm{~J}$; and other parameters remained the same (laser spot diameter of $2 \mathrm{~mm}$, laser pulse width of $20 \mathrm{~ns}$, laser spot overlap rate of $30 \%$, and oblique shock angle of $60^{\circ}$ ). Figure 14 shows contours of the residual stress distribution of S11 on surface of Ni-based alloy GH4169 specimen under three different laser energies. The maximum values of compressive residual stress on material surface of energy combinations I, II, III, and IV were $-497 \mathrm{MPa},-552.2 \mathrm{MPa}$, $-629.7 \mathrm{MPa}$, and $-697.6 \mathrm{MPa}$, respectively. According to the above statement, it could be seen that the maximum value of compressive residual stress on surface of energy combination II was increased by $11.1 \%$ compared with that of energy 


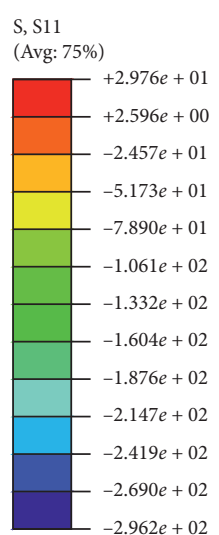

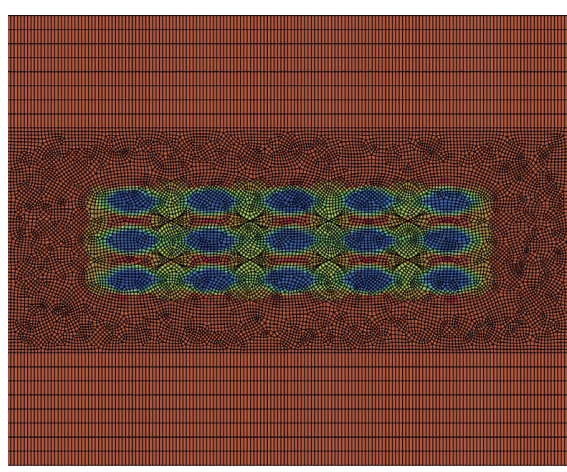

(a)
S, S11

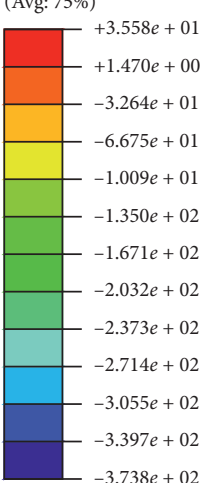

$-3.738 e+02$

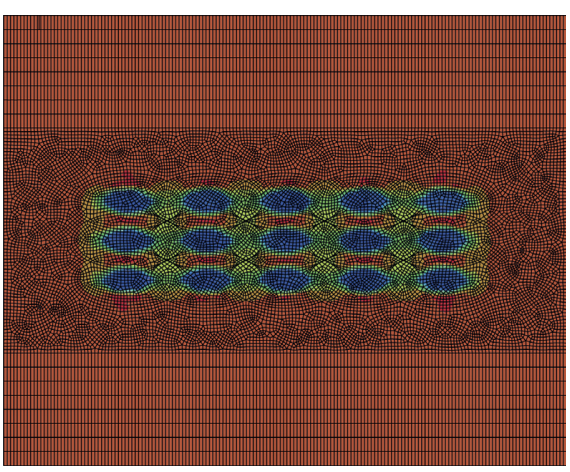

(b)

\section{S, S11}
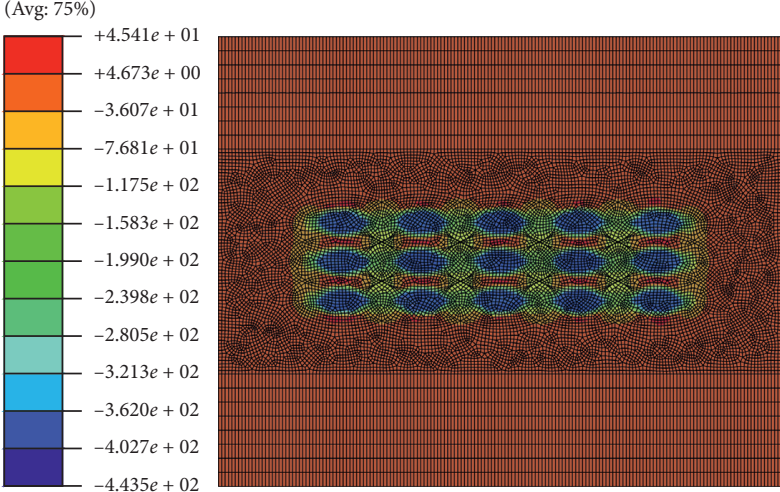

(c)

Figure 6: Contours of residual stress distribution of sample surface with different laser power. (a) $5 \mathrm{~J}$, (b) $6 \mathrm{~J}$, and (c) $7 \mathrm{~J}$.

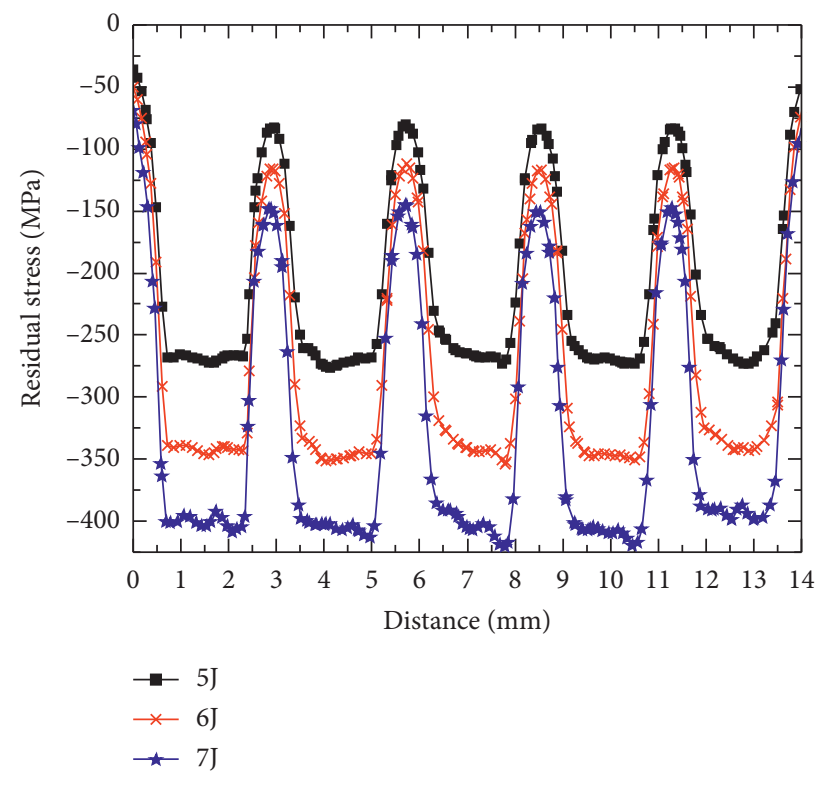

FIgURE 7: Curves of residual stress distribution of sample surface with different laser power.

combination I, while the maximum value of compressive residual stress on surface of energy combination III was increased by $26.7 \%$ compared with that of energy combination I, and it was close to that of energy combination IV. It is shown that LSP with gradient energy could have a better strengthening effect. Using the same method of 


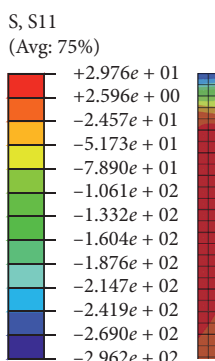

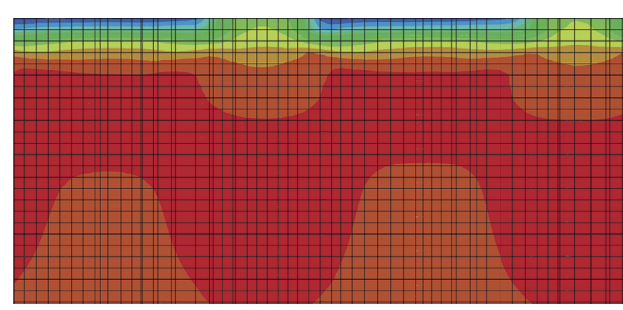

(a)

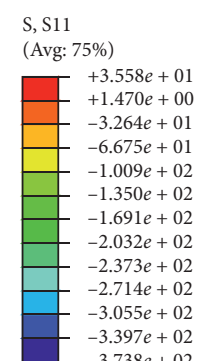

$-3.738 e+02$

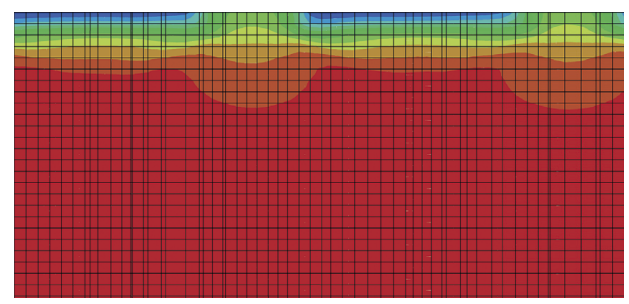

(b)

S, S11
(Avg: $75 \%)$

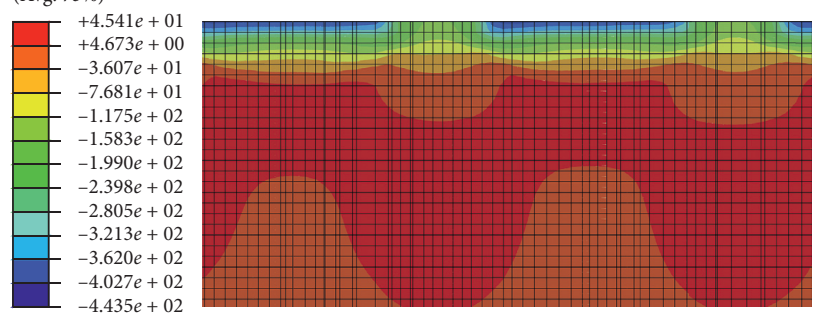

(c)

FIGURE 8: Contours of residual stress distribution in-depth direction of sample surface with different laser power. (a) $5 \mathrm{~J}$, (b) $6 \mathrm{~J}$, and (c) $7 \mathrm{~J}$.

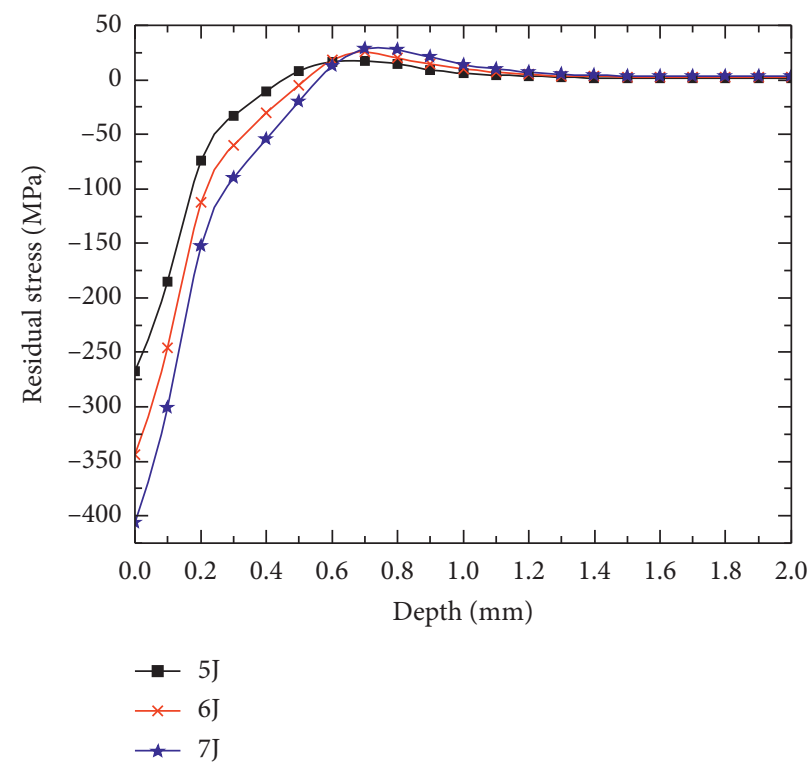

FIGURE 9: Curves of residual stress distribution in-depth direction of sample surface with different laser power.

selecting path $X$ as in Figure 8, the residual stress distribution state curves of material surface with three different energies as shown in Figure 15 were obtained. During the transition of energy combination from I-II-III-IV, the residual stress field on surface of material shock area also always had some approximately uniformly distributed areas, and the uniformity continued to decrease with increase of energy in combination, and the unevenness of light intensity was more obvious. The compressive residual stress on the overlapping part of the spot was significantly smaller than that on the central part of the spot.
Figure 16 shows contours of the residual stress distribution of S11 in-depth direction of the Ni-based alloy GH4169 specimen under three different laser energies. It could be seen that the Ni-based alloy GH4169 sample would have a changed in-depth direction. A certain range of compressive residual stress was formed. During the transformation of energy combination from I-II-III$\mathrm{IV}$, the residual compressive stress influence deepened, and the range of compressive residual stress would be larger. Figure 17 shows the residual stress distribution curves in the in-depth direction of material under energy 


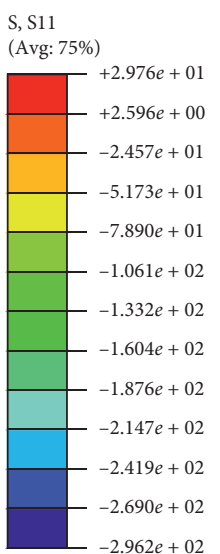

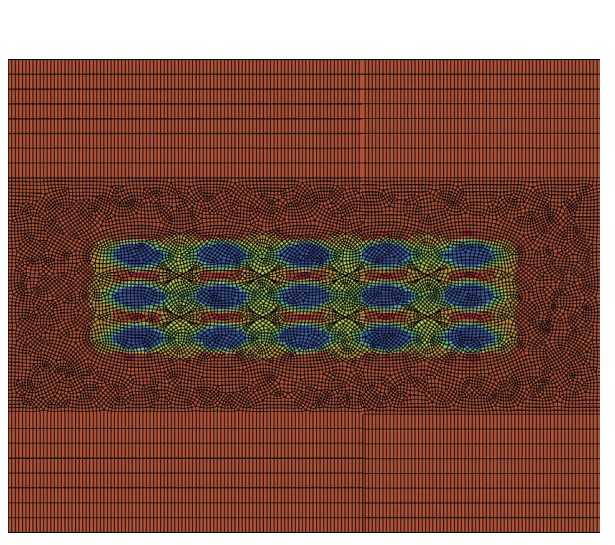

(a)
S, S11

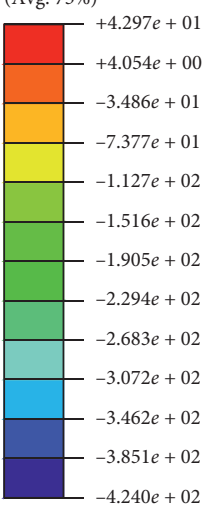

$-4.240 e+02$

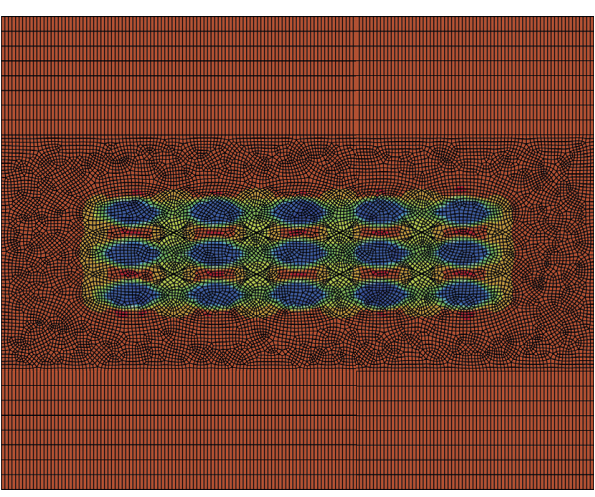

(b)
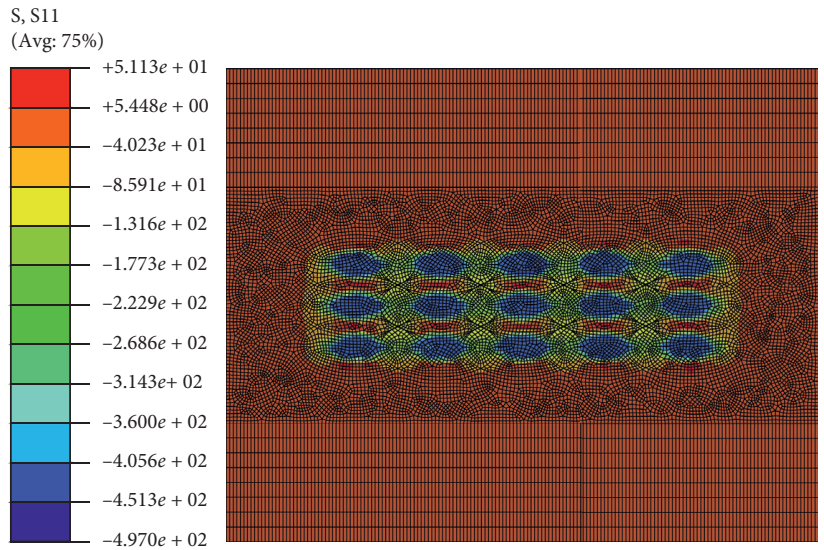

(c)

FIGURE 10: Contours of residual stress distribution of sample surface with different number of shocks. (a) 1 shock, (b) 2 shocks, and (c) 3 shocks.

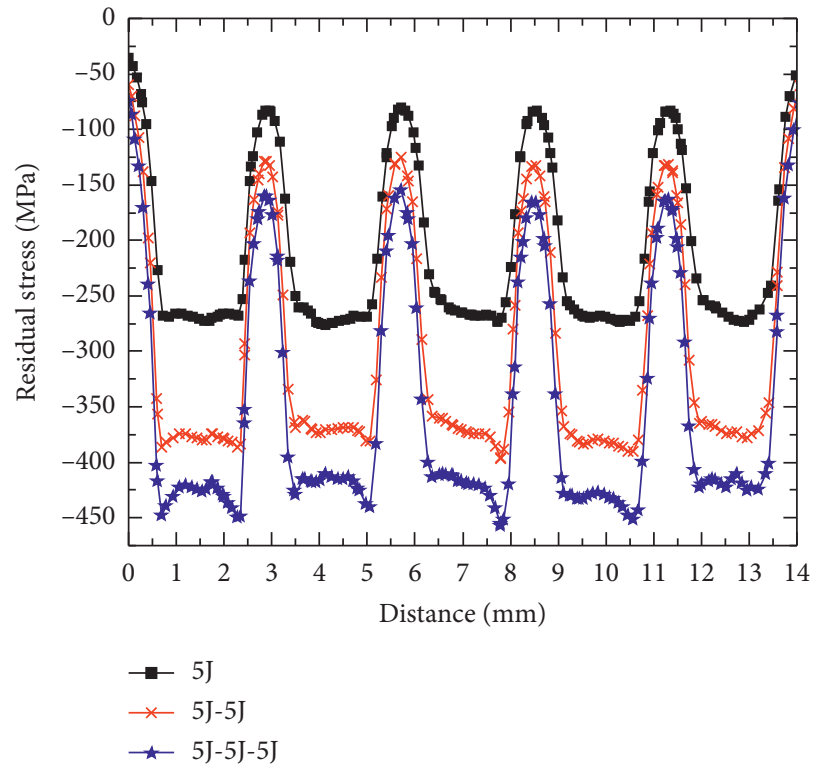

FIGURE 11: Curves of residual stress distribution of sample surface with different number of shocks. 


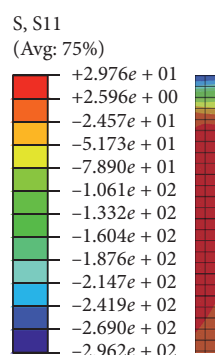

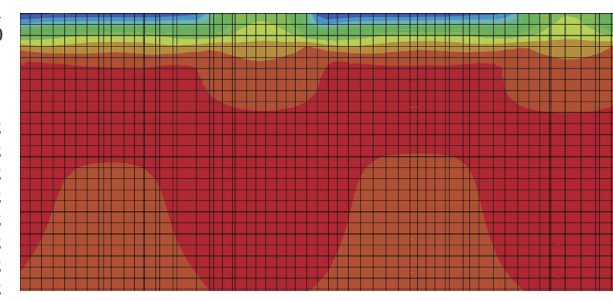

(a)
S, S11

(Avg: 75\%)

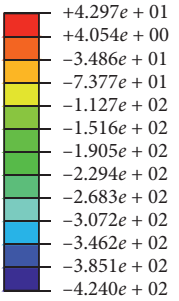

$-4.240 e+02$

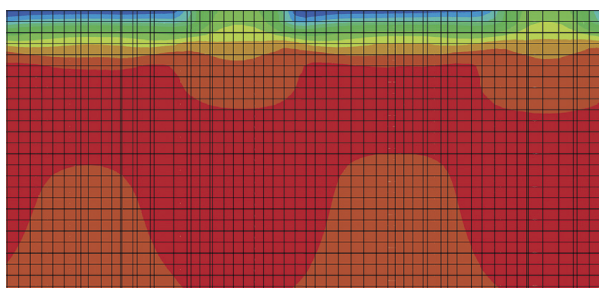

(b)

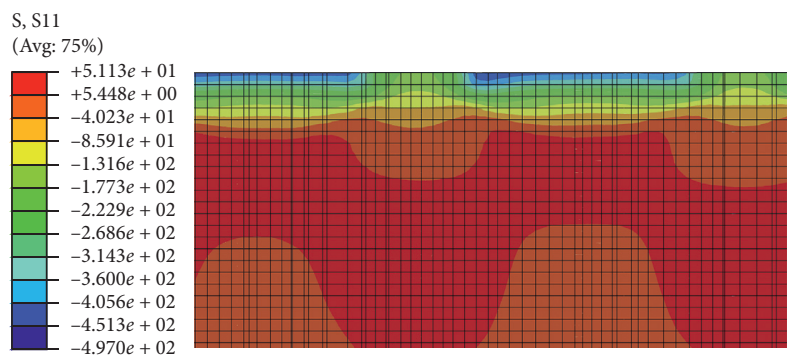

(c)

Figure 12: Contours of residual stress distribution of the in-depth direction of sample surface with different number of shocks. (a) 1 shock, (b) 2 shocks, and (c) 3 shocks.

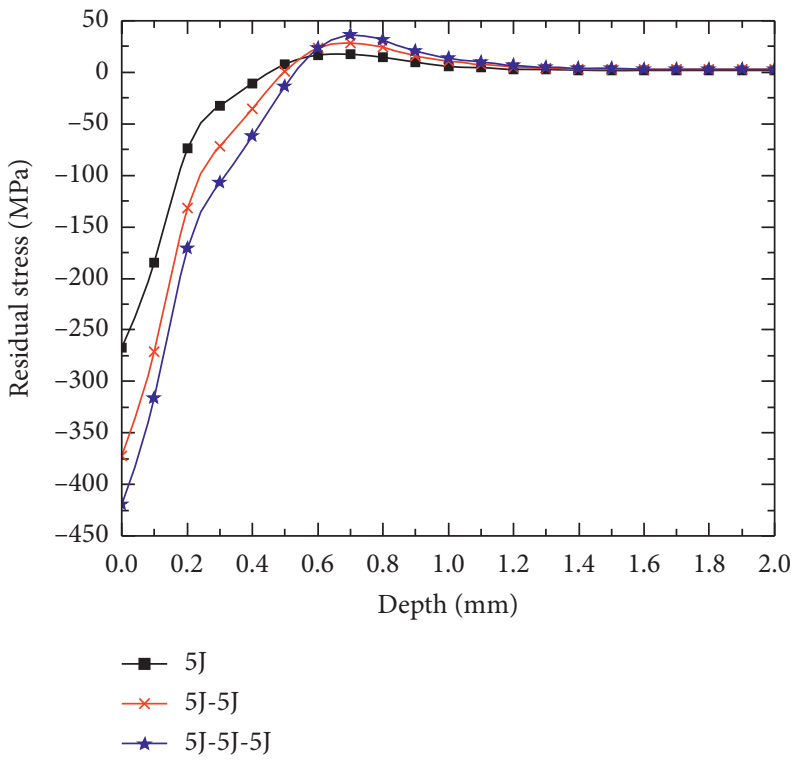

FIgURE 13: Curves of residual stress distribution of the in-depth direction of sample surface with different number of shocks.

combinations I, II, III, and IV. It could be seen from the figure that the values of range of depth of compressive residual stress of energy combinations I, II, III, and IV were $0.537 \mathrm{~mm}, 0.562 \mathrm{~mm}, 0.601 \mathrm{~mm}$, and $0.647 \mathrm{~mm}$, respectively. The value of range of depth of compressive residual stress of energy combination II was increased by $4.7 \%$ compared with that of energy combination I, while the value of range of depth of compressive residual stress of energy combination III was increased by $11.9 \%$ compared with that of energy combination I, and it was close to that of energy combination IV. It is shown further that using gradient energy for LSP could have a better strengthening effect.

\section{Experiments}

Firstly, a specimen of Ni-based alloy GH4169 with a size of $20 \mathrm{~mm} \times 20 \mathrm{~mm} \times 12 \mathrm{~mm}$ was made by wire cutting machine before the experiment. Secondly, in order to remove burrs and scratches in surface of the specimen, it was sanded with sandpaper of different roughness (\#180, \#400, \#1000, \#2000, and \#3000). Thirdly, it was polished to make the surface 


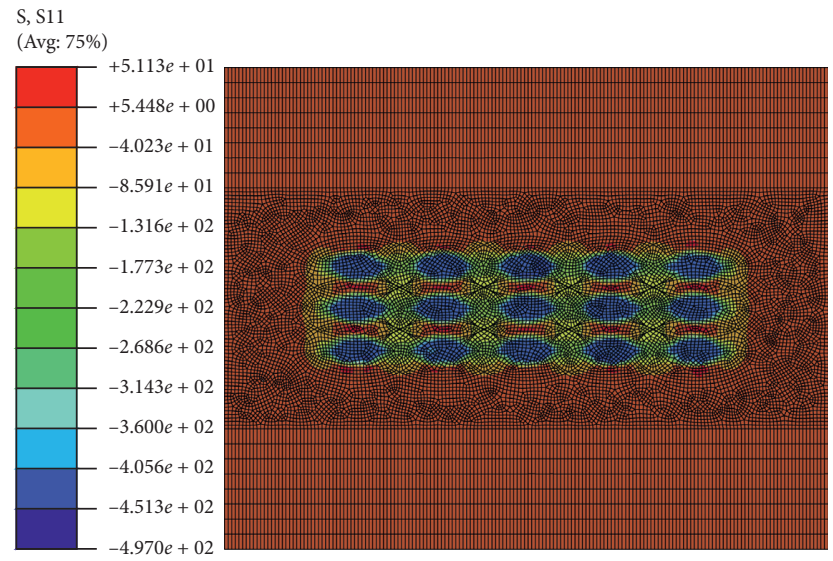

(a)

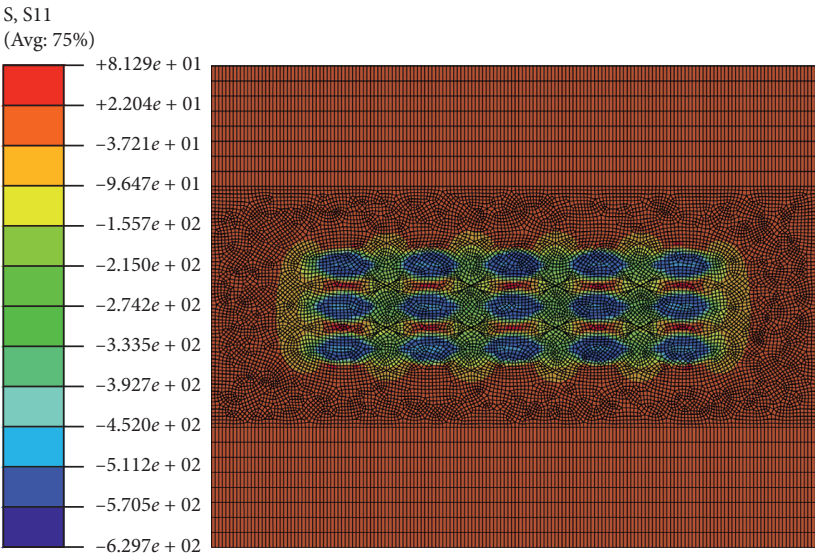

(c)

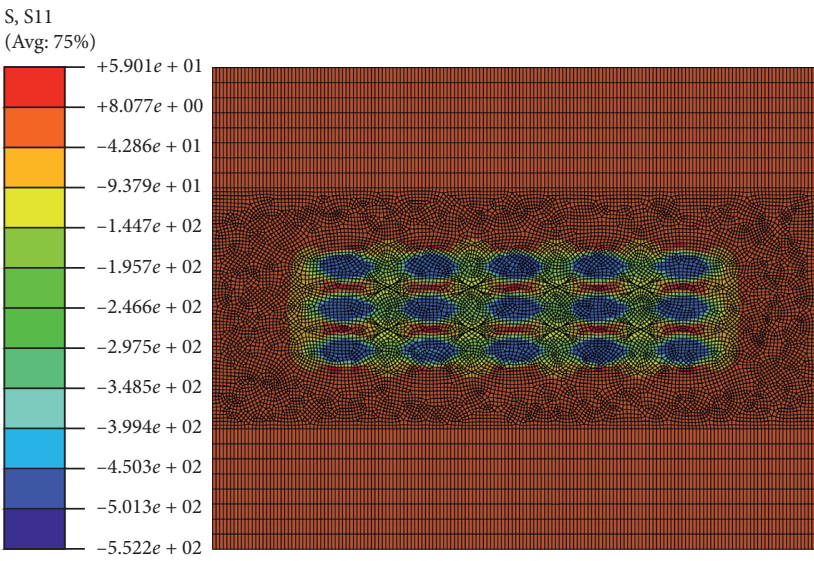

(b)

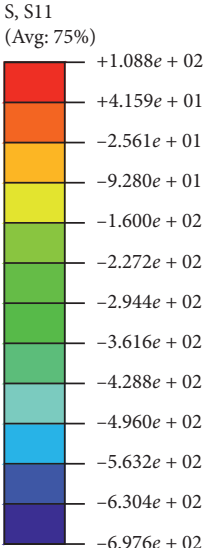

$-6.976 e+02$

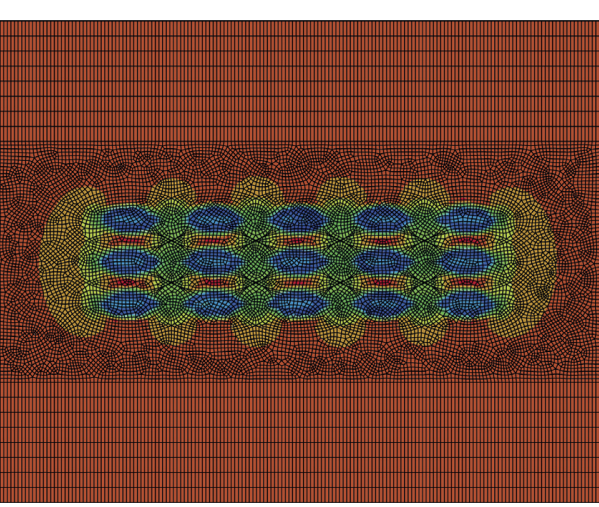

(d)

Figure 14: Contours of residual stress distribution of sample surface with three different laser energies. (a) $5 \mathrm{~J}$, $5 \mathrm{~J}, 5 \mathrm{~J}$; (b) $5 \mathrm{~J}, 5 \mathrm{~J}, 6 \mathrm{~J}$; (c) $5 \mathrm{~J}$, $6 \mathrm{~J}, 7 \mathrm{~J}$; (d) $7 \mathrm{~J}, 7 \mathrm{~J}, 7 \mathrm{~J}$.

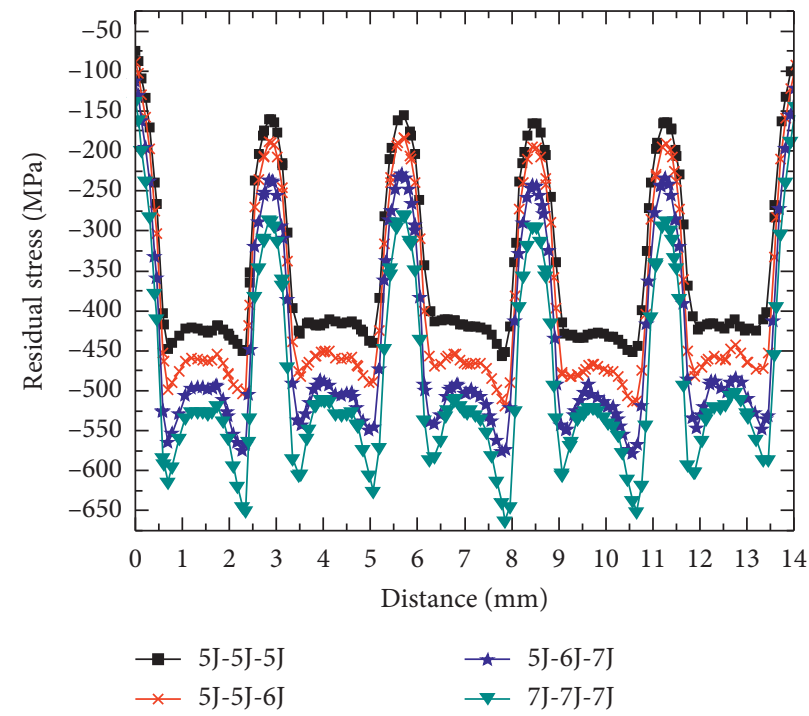

FIgURE 15: Curves of residual stress distribution of the in-depth direction of sample surface with three different laser energies.

smooth. Fourthly, the specimen was put into an ultrasonic cleaning machine filled with anhydrous ethanol solution and cleaned with ultrasonics to remove surface stains. Finally, the surface of the sample was dried with a hair dryer and pasted with black tape. The experimental parameters in this paper were laser energy of $6 \mathrm{~J}$, spot diameter of $2 \mathrm{~mm}$, pulse 

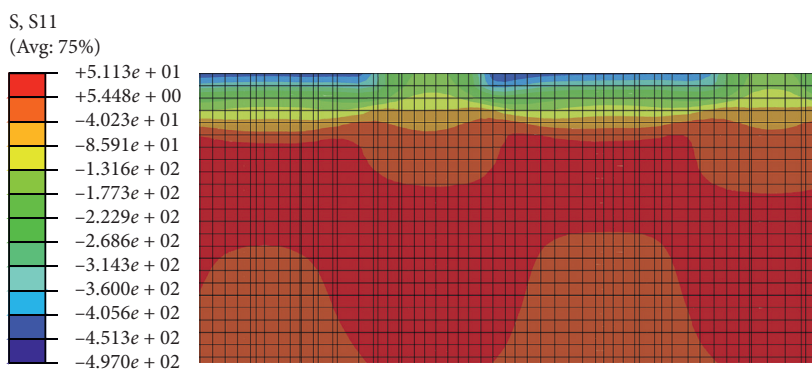

(a)
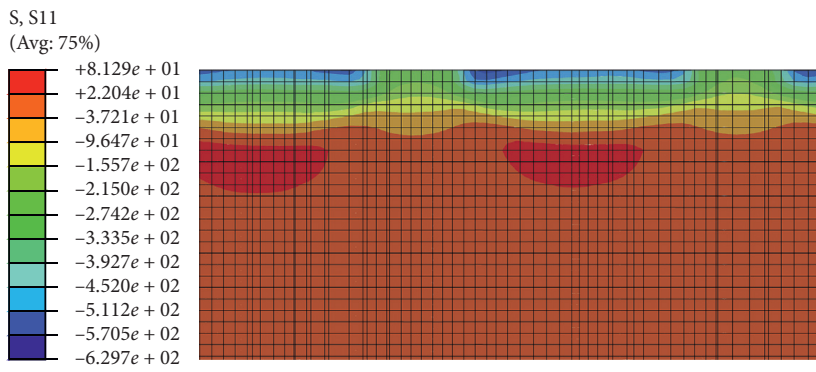

(c)

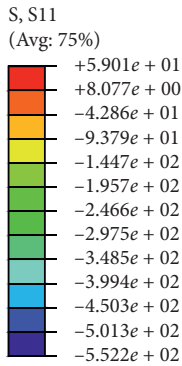

$-5.522 e+02$

S, S11

(Avg: 75\%)

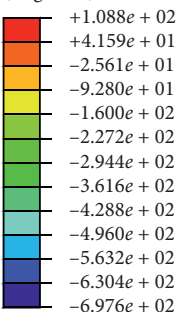

$-6.976 e+02$

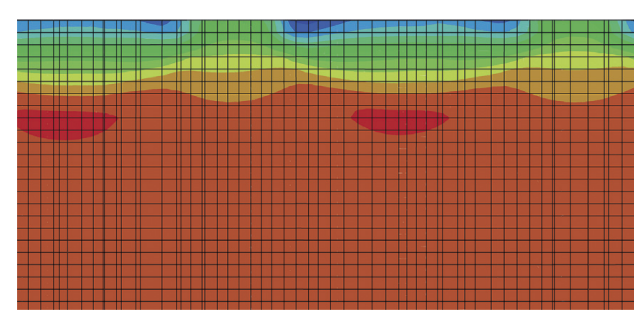

(d)

Figure 16: Contours of residual stress distribution of the in-depth direction of sample surface with three different laser energies. (a) $5 \mathrm{~J}$, $5 \mathrm{~J}$, $5 \mathrm{~J}$; (b) $5 \mathrm{~J}, 5 \mathrm{~J}, 6 \mathrm{~J}$; (c) $5 \mathrm{~J}, 6 \mathrm{~J}, 7 \mathrm{~J}$; (d) $7 \mathrm{~J}, 7 \mathrm{~J}, 7 \mathrm{~J}$.

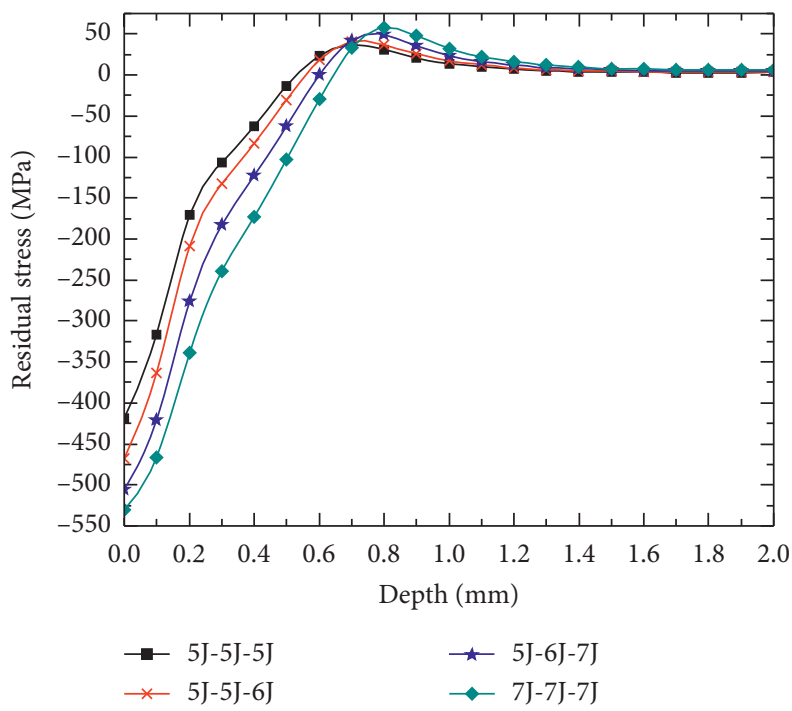

FIgURE 17: Curves of residual stress distribution of the in-depth direction of sample surface with three different laser energies.

width of $20 \mathrm{~ns}$, shocking number of 1 , overlap rate of $30 \%$, and oblique impact angle of $60^{\circ}$. The experiment of LSP used the Procudo ${ }^{\circledR} 200$ Laser Peening System produced by LSP Technologies, Inc. The sample of Ni-based alloy GH4169 was fixed on the positioning plate of the robot arm of Procudo ${ }^{\circledR}$ 200 Laser Peening System by a clamp, as shown in Figure 18. The mechanical arm was adjusted so that the laser beam formed an angle of $60^{\circ}$ with the surface of shock area of sample. Figure 19 shows the surface morphology of sample after LSP. Comparing the method of selecting path $X$ in Figure 6(a), the residual stress of the specimen surface was tested along the center of the spot by X-ray diffraction with $\sin 2 \psi$ method. The residual stress was measured by the XL640 X-ray stress meter produced by Handan Este Company in China. The $X$ light tube voltage and current were set to $26 \mathrm{kV}$ and $8 \mathrm{~mA}$, respectively. Counting time was $60 \mathrm{~s}$. The $\mathrm{X}$-ray source was $\mathrm{CrK} \beta$ ray and the diffraction plane was a phase (311) plane. The feed angle of the ladder scanning was $0.04 / \mathrm{s}$. The scanning starting angle and ending angle were $149^{\circ}$ and $157^{\circ}$, respectively. The residual stress in-depth direction of sample was obtained by electrolyzing the surface of sample. The numerical simulation and the experimental 


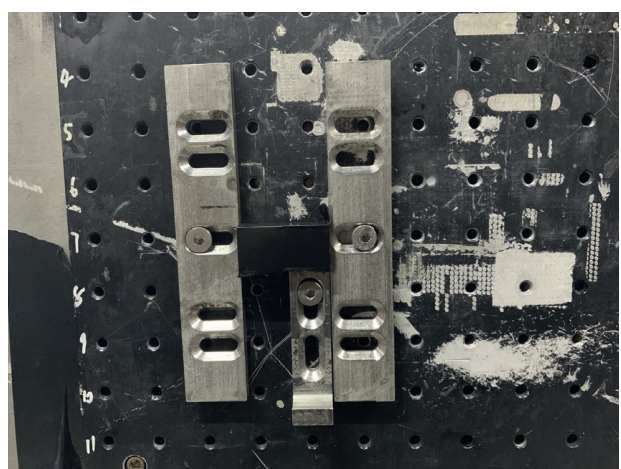

FIGURE 18: Schematic of Ni-based alloy GH4169 clamping.

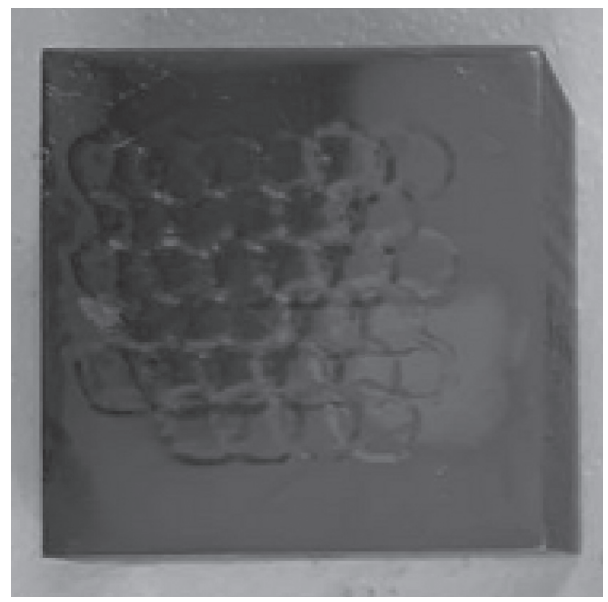

Figure 19: Morphology of sample of LSP.

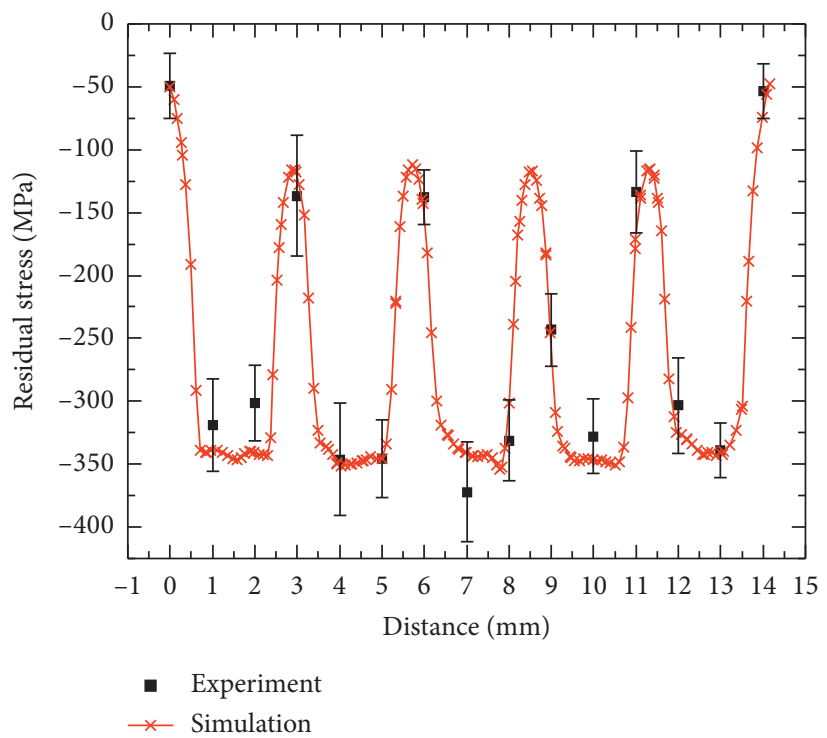

Figure 20: Residual stress distribution curves of material surface.

test results were in good agreement. The finite element model established for the flat-topped laser oblique shock was verified. Figure 20 shows the residual stress distribution curves of the material surface by numerical simulation and experimental test. Figure 21 shows the residual stress distribution in-depth direction of the material by numerical 


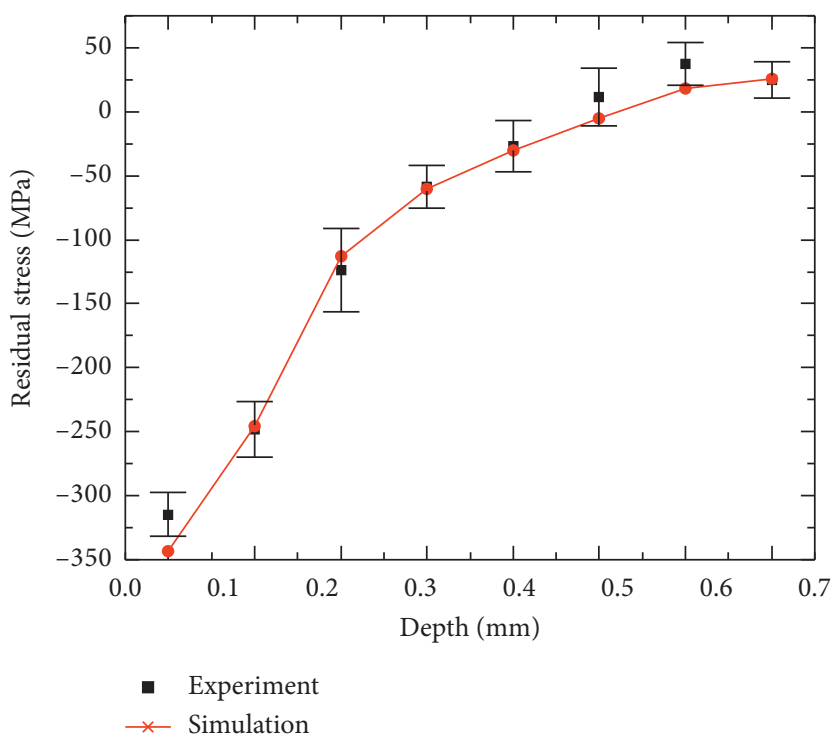

FIgURE 21: Residual stress distribution curves of the in-depth direction of the material.

simulation and experiment test. There was a deviation between test data and the simulation data of residual stress, which might be caused by the original stress on the surface and depth of the material before LSP.

\section{Conclusion}

In this paper, a finite element analysis model of flat-topped laser oblique shock was established by ABAQUS software, and the effects of different laser energy and different shocking number on the residual stress field of Ni-based alloy GH4169 of LSP were discussed. The conclusions obtained were as follows:

Three-dimensional finite element analysis used superGaussian beam distribution to construct the spatial distribution model of shock waves. The simulation results were in good agreement with the experimental results. The research results will provide a theoretical basis for LSP of turbine disk mortise.

Compressive residual stress in the surface and the depth of material increased with the increase of the laser energy and the shocking numbers; since material will be hardened after laser shock processing, increasing the laser energy after two shock processings or adopting a gradient energy combination for laser shock processing can more effectively improve the performance of the material surface and make the effect of laser shock processing better.

\section{Data Availability}

The data used to support the findings of this study are included within the article.

\section{Conflicts of Interest}

The authors declare that they have no conflicts of interest.

\section{Acknowledgments}

This research was funded by the National Natural Science Foundation of China (Grant no. U1608259) and Science and Technology Project of Guangdong Province of China (Grant no. 2017B090911013).

\section{References}

[1] H. Li, S. Niu, Q. Zhang, S. Fu, and N. Qu, "Investigation of material removal in inner-jet electrochemical grinding of GH4169 alloy," Scientific Reports, vol. 7, Article ID 3482, 2017.

[2] A. Waseem, J. Sun, and W. Chen, "Effect of machining parameters on surface integrity in high speed milling of super alloy GH4169/Inconel 718," Mater Manuf Process, vol. 31, pp. 620-627, 2016.

[3] H. J. Lim, Y. Sohn, and Y. Kim, "Data-driven fatigue crack quantification and prognosis using nonlinear ultrasonic modulation," Mechanical Systems and Signal Processing, vol. 109, pp. 185-195, 2018.

[4] H. E. Coules, G. C. M. Horne, K. Abburi Venkata, and T. Pirling, "The effects of residual stress on elastic-plastic fracture propagation and stability," Materials \& Design, vol. 143, pp. 131-140, 2018.

[5] L. Zhou, C. Long, W. He, L. Tian, and W. Jia, "Improvement of high-temperature fatigue performance in the nickel-based alloy by LSP-induced surface nanocrystallization," Journal of Alloys and Compounds, vol. 744, pp. 156-164, 2018.

[6] H. Y. Li, H. L. Sun, P. Bowen, and J. F. Knott, "Effects of compressive residual stress on short fatigue crack growth in a nickel-based superalloy," International Journal of Fatigue, vol. 108, pp. 53-61, 2018.

[7] P. Zhang and Z. Liu, "Enhancing surface integrity and corrosion resistance of laser cladded $\mathrm{Cr}-\mathrm{Ni}$ alloys by hard turning and low plasticity burnishing," Applied Surface Science, vol. 409, pp. 169-178, 2017.

[8] X. Yuan and C. Li, "An engineering high cycle fatigue strength prediction model for low plasticity burnished samples," International Journal of Fatigue, vol. 103, pp. 318-326, 2017. 
[9] S. Khalil, F. G. Hossein, and M. Amir Hossein, "Effect of initial surface treatment on shot peening residual stress field: analytical approach with experimental verification," Journal of Mechanical Sciences, vol. 137, pp. 171-181, 2018.

[10] X. D. Ren, Q. B. Zhan, S. Q. Yuan et al., "A finite element analysis of thermal relaxation of residual stress in laser shock processing Ni-based alloy GH4169," Materials \& Design (1980-2015), vol. 54, pp. 708-711, 2014.

[11] Y. Yang, H. Zhang, and H. Qiao, "Microstructure characteristics and formation mechanism of TC17 titanium alloy induced by laser shock processing," Journal of Alloys and Compounds, vol. 722, pp. 509-516, 2017.

[12] D. Karthik and S. Swaroop, "Laser shock peening enhanced corrosion properties in a nickel based Inconel 600 superalloy," Journal of Alloys and Compounds, vol. 694, pp. 1309-1319, 2017.

[13] J. Cao, J. Zhang, Y. Hua, R. Chen, and Y. Ye, "Improving the high temperature oxidation resistance of Ni-based superalloy GH202 induced by laser shock processing," Journal of Materials Processing Technology, vol. 243, pp. 31-39, 2017.

[14] K. Micheal, M. S. Ramaiah, D. Qian, and K. Vasudevan Vijay, "Effect of laser shock peening on residual stress, microstructure and fatigue behavior of ATI 718Plus alloy," International Journal of Fatigue, vol. 102, pp. 121-134, 2017.

[15] W. F. Zhou, X. D. Ren, Y. P. Ren, S. D. Xu, J. J. Huang, and T. Yang, "Laser shock processing on Ni-based superalloy K417 and its effect on thermal relaxation of residual stress," The International Journal of Advanced Manufacturing Technology, vol. 88, no. 1-4, pp. 675-681, 2017.

[16] H. Xianliang, W. Jiajun, Z. Jibin et al., "Numerical simulation of the surface morphology and residual stress field of IN718 alloy by Gaussian mode laser shock," Optik, vol. 207, Article ID 164441, 2020.

[17] K. Y. Luo, J. Z. Lu, Q. W. Wang, M. Luo, H. Qi, and J. Z. Zhou, "Residual stress distribution of Ti-6Al-4V alloy under different ns-LSP processing parameters," Applied Surface Science, vol. 285, pp. 607-615, 2013.

[18] C. Wang, Y. X. Wang, and Z. Gao, "Numerical modeling of the confined laser shock peening of the OFHC copper," International Journal of Mechanical Sciences, vol. 108-109, pp. 104-114, 2016.

[19] Y. Hu and Z. Yao, "Numerical simulation and experimentation of overlapping laser shock processing with symmetry cell," International Journal of Machine Tools and Manufacture, vol. 48, no. 2, pp. 152-162, 2008.

[20] N. Hfaiedh, H. P. Peyre, and V. I. JiPopa, "Finite element analysis of laser shock peening of 2050-T8 aluminum alloy," International Journal of Fatigue, vol. 70, pp. 480-489, 2015.

[21] P. Vignal, A. Sollier, I. Chaieb et al., "FEM simulation of residual stresses induced by laser Peening," The European Physical Journal Applied Physics, vol. 23, no. 2, pp. 83-88, 2003.

[22] C. Correa, L. Ruiz de Lara, M. Díaz, A. Gil-Santos, J. A. Porro, and J. L. Ocaña, "Effect of advancing direction on fatigue life of 316L stainless steel specimens treated by double-sided laser shock peening," International Journal of Fatigue, vol. 79, pp. 1-9, 2015.

[23] X. Yang, W. Li, J. Li, T. Ma, and J. Guo, "FEM analysis of temperature distribution and experimental study of microstructure evolution in friction interface of GH4169 superalloy," Materials \& Design, vol. 84, pp. 133-143, 2015.

[24] M. R. Perrone, A. Piegari, and S. Scaglione, "On the superGaussian unstable resonators for high-gain short-pulse laser media," IEEE Journal of Quantum Electronics, vol. 29, no. 5, pp. 1423-1487, 1993.

[25] H. Qiao, B. Sun, J. Zhao et al., "Numerical modeling of residual stress field for linear polarized laser oblique shock peening," Optik-International Journal for Light and Electron Optics, vol. 186, pp. 52-62, 2019.

[26] Y. Cai and Q. Lin, "Properties of a flattened Gaussian beam in the fractional Fourier transform plane," Journal of Optics A: Pure and Applied Optics, vol. 5, no. 3, p. 272, 2003. 